\title{
Inspirational leaders
}

In this Feature article by Kathy Oxtoby (BMJ 2012;344:e3062, doi:10.1136/bmj.e3062) the surname of one of the doctors shortlisted for the Clinical Leader of the Year award was misspelt. It should have been Duwarakan Satchithananda [not Satchithanand].
Cite this as: BMJ 2012;344:e3376

๑ BMJ Publishing Group Ltd 2012 